\title{
Organizational Stress Indicators and Influence on Academic Performance in Private Universities among Academic Personnel
}

\author{
Midya Yousefi, Rohini Devi*, Ahmad Shuib \\ Binary University College of Management \& Entrepreneurship, Malaysia
}

Received October 24, 2019; Revised January 21, 2020; Accepted February 25, 2020

Copyright $\subseteq 2020$ by authors, all rights reserved. Authors agree that this article remains permanently open access under the terms of the Creative Commons Attribution License 4.0 International License

\begin{abstract}
In the last several years, the Private universities in Malaysia have undergone a wide range of reconstruction and developed programme that has been increasing organizational stress experienced by academics. This study investigates to recognize and test the influence of organizational indicators of stress on the academic performance. The current research collected questionnaire via many cluster sampling techniques from 32 Malaysian private universities academic staff. Also, 190 completed questionnaires were analysed through SmartPLS software that has delivered the results based on measurement and structural model. Then outcomes show that workload is the first stress organizational indictors that has adverse effect on academic staff work performance. Likewise, ambiguity and conflict in roles are the secondary and thirdly stress indictors that negatively influence the academics' performance in private universities respectively. This study suggests remarkable implications both theoretically and practically to complement the available literature toward the organizational stress indicators in academia context that contribute to academic staff performance. In addition, it enriches current administrators and policy makers of private universities in reducing the negative effects of stress predictors in organization and manage to increase academic staff performance.
\end{abstract}

Keywords Organizational Stress Indicators, Workload, Role Ambiguity, Role Conflict, Academic Performance, Private University, Partial Least Square

\section{Introduction}

Organizational stress has been a growing problem recently and it is a major issue in the higher academic institutions that have negative impacts on academic performance, while academic staff play fundamental role in creating, building and developing knowledge and innovating with teaching and training (Ling, 2014). According to Winter et al. (2000), university staff who works as lecturer, senior lecturer, associate professor and full professor faced institutional demands pressures to publish articles and obtain external funding, thus increasing their work-load and time constraints even more further globally and more than $64 \%$ of these staff encountered at least one of the stress indictors that flows in academia's arena.

Meanwhile, based on World Health organization (2016), $71 \%$ of university academics reflected that their jobs are very stressful and that their jobs are more over the past 10 years in UK. Also, from other researches on organizational stress that conducted in Asia, academics subjected to these stress indicators are more than $69 \%$ in Chinese and Japanese universities. (Lin li, 2012). However, 86\% of faculty staff in US universities found their workplace very stressful (Moller, 2009). Meantime, in a Canada, New Zealand and Australia, work stress for academic members reported more than 65\% in universities (Catano et al., 2007).

Likewise, being effective in universities as faculty staff depends on a crystal-clear path of how to combine the elements of research and teaching also, service in a way that makes the best use of the time (Jacob et al., 2015). Therefore, universities passing through the transition of constant changes globally, academics received organizational stress more that past, especially dynamic changing in multitask duties and curriculum design, resulting in high-performance expectation to be met in academic workplace (Kaur et al., 2018).

Hence, in a bid to enhance performance in universities, the academics not only work more to boost their outcome such as teaching activities, production of papers for publication in high impact journals, application of research 
fund locally and internationally, but also supervise students in research and thesis. In addition, regarding to Murphy (2014), stress in organizations like universities has no longer provided low level indicators that adversely impact on academic staff performance and should have more concerns on this issues that radically increased among universities personnel in the world.

\section{Literature Review}

The target of this research is to understand the notions of WL, RA and RC that are very challenging recently as if associated adversely on academic performance in private universities. Hence, above highlighted, regarding the importance of job performance for overall performance of universities, then the current research aims to serve agenda as steppingstone guidelines for future researches in diverse dimensions of improving the productivity and meantime the quality of academics in universities.

Therefore, to achieve this purpose the difference of organizational stress indicators that flows in private universities is recognized and understood. In this research, the following objectives were assessed:

1. To assess the influence of the workload on performance among academic staff.

2. To examine the effect of role conflict towards performance among academic staff.

3. To determine the impact of role ambiguity on performance among academic staff.

The present study focuses on academic job performance among academic staffs. The university is an organization and performance structures are investigated. A university is a social system which is made up of a range of individuals or agents whose work contributes to wider organisational actions. In framing this study, it is important to consider the ways in which individuals are understood in relation to universities academic staff performance.

\subsection{Universities Performance and Stress Indicators}

According to Jonker (2016), developed countries such as the UK, Australia and US the global changing in curriculum design and an increasing number of students especially in postgraduate positions have led to a notable demand in universities and increase job pressures of academics, as well as developing countries such as Malaysia and Indonesia.

Also, the difference between types of universities could be an element that makes the difference in levels of WL, RA and RC that result in job performance directly university academic personnel, and based on the this phenomenon, it should be highlighted here that there is a major issue in research to recognize and eliminate organizational stressors that negatively influence on the academic staff performance who work in universities in Malaysia (Yousefi \& Abdullah, 2019).

Therefore, this aspect can be achieved by clarifying and understanding the difference of stress indicators that scattered in private universities. According to Baron and Greenberg (2003), ambiguities in role remains more popular and it is considered more common than role conflictions among employees in private organizations and most staff cannot distinguish whether they encountered with role confliction or ambiguity in workplace; in addition, they remarked that due to the lake of distinction between RA and RC stressors staff faced obstacles on how to cope with it.

Dualistic system in higher education in Malaysian contain public and private institutions and universities. In addition, currently, both of them co-existed within the higher education sector in Malaysia. Therefore, the market share is captured by both system of private and public sectors; therefore, these intuitions have shifted remarkably recently. However, the analysis of the relationship is divided into three major components of higher education that include schools, students and courses they offered (Fernandez, 2010).

Furthermore, Ahsan et al. (2009) stated that while the number of universities in Malaysia has increased hugely in the recent years, the increasing number of universities, academic personnel may face more challenges and problems in their workplace as the top management of Malaysian universities is faced with pressure from other universities competitiveness. Accordingly, plenty of universities are setting new goals to compete with other universities nowadays, and therefore the academics are evolving with the goal to boost the overall performance of these universities.

Henceforth, this may cause university academic personnel to encounter multitude stressors regarding their job expectations. Therefore, the three elements of the academic work which involved teaching, research and learning not only have caused complexity as it demands a deeper understanding of the nature of student learning, pressures to the relocation of the teaching and research environment around learning outcomes, and due to demand of certain courses that require a professional approach in university teaching but also, private universities at the same time play the role of competitor to public institutions Malaysia (Yousefi \& Abdullah, 2019). Hence, the medium of instruction in private institutions is English while Malay language continues to be the official medium of instruction in public institutions; this difference has created some comparative advantage for students to pursue higher education in private institutions. In addition, many of these private institutions have twinning programmes with foreign universities which confer the degrees and increasing in the number of students that directly have the resulted-on workload, role ambiguity and conflicts of academic staff (Ahsan et al., 2009). 
All in all, private universities operate much on a platform with a combination of competitive and complementary elements; more like a hybrid of teaching, research and learning elements and the stress is more heightened in fivestar ranking universities as they need to maintain the status and produce articles that must be published in high impact journals then publication process has an extra pressure on academics performance. Thus, the uniqueness of the study would undoubtedly add more knowledge to the field and it would also raise the awareness to recognize stress indicators in private universities.

\section{Method}

\subsection{Research Design}

According to Maree (2010), cross-sectional research is suitable particularly for examining the prevalence of a treatment in a population; likewise, current article demonstrate research based on the cross-sectional type and investigated all the data collection at one snapshot of time. Also, an explanatory research design using a survey strategy through self-administered structured questionnaires was employed as the survey instrument. Therefore, many problems arise from ambiguous sentences, terms and words also, Pre-test carried out in the present study via the debriefing techniques from personal interviews regarding of reducing biases (Sekaran \& Bougie, 2010).

\subsection{Population and Sampling Technique}

The population for the current research involves academic staff who work in Malaysian private universities. Thus, there are 33 private universities spread from north to south of Malaysia, and a full-scale university is categorized as either a teaching only university or a teaching and research university.

This study chose to examine private universities only in Malaysia because of the presence of two job performance components: teaching and research. Therefore, public universities academics in Malaysia are not included because it was believed that the sources of organizational stress for public universities might be significantly different due to factors such as accountability to different mission and vision, sources of funding, profit orientation and performance dimensions (Triantafillou, 2004). Hence, productivity is generally measured in these components, and their presence is important for the effectiveness of these private universities strengthens the teaching programmes in this study.

This study adopted the questionnaire that contains four parts (i.e. Workload, Role Ambiguity and Role Conflict) for measuring the organizational indicators of stress and
(Job Performance) measured the academic performance based on the teaching and research domain. Moreover, the current research selected private universities from the three regions of Malaysia for data collection. Therefore, using cluster sampling method, this research is to identified data collection location by divided the universities based on geographical dispersion. Furthermore, as Ochoa (2017) has revealed, using cluster sampling has advantages because it is effective in primary data collection from geographically dispersed population and the need for division by location. Besides, among 190 participants, (58.3\%) of them were lecturers, followed by $(18.8 \%)$ professors and (11.9\%) participants who were senior lectures, while only $(11.4 \%)$ were associated professors.

\subsection{Instruments}

Validity and reliability of the current study questionnaires were analyzed via pre and post Test due to the sensitivity of organizational stress natures. In addition, three exogenous variables were assessed in the current framework: workload, role conflict and role ambiguity with one endogenous variable and job performance. Likewise, before testing hypothesis testing, it is essential to scrutinize measurement model to verify that the model is fit. Although, the only criterion that can assessed approximately model fit for SmartPLS currently, is the standardized root mean square residual (SRMR). Finally, the present study demonstrated reflective model, relying Hair et al. (2011) employed convergent validity through examining the indicator loading via average variance explained (AVE) and composite reliability (CR). Totally, the measurement model for the current framework of academics who work in Malaysian private universities adequately established AVE and CR.

\subsection{Data Analysis}

In order to examine whether organizational stress predictors' (stressors) including (WL, RA and RC) had adversely impacts on academics' performance in private universities, it was first tested whether the data showed a normal distribution. Therefore, this study applied the Smart PLS to measure the hypotheses and implemented guidelines suggested by Hair et al. (2013) to report the findings.

\subsection{Measurement Model}

In this framework, there were three exogenous variables: WL, RA, RC and JP were the endogenous variable. Therefore, before conducting hypothesis testing, it is critical to examine the measurement model to certify whether the model is fit. Hence, checking loadings have shown that, only one items of RA (item: RA 2), two items of WL (items: WL 1 and 2) were below the threshold. 
According to Henseler et al. (2016) SRMR could serve as a goodness of fit measure for PLS-SEM then; in the current framework, the results indicate that SRMR value is 0.059 which is less than cut-off value of 0.08 .

Also, because the current model contained reflective scale measurement, convergent validity was assessed by examining the indicator loading, average variance explained (AVE) and composite reliability (CR ).

Consequently, the results indicated that the AVE for each latent variable was above cut off value 0.50. The AVE in the current study ranged from 0.699 (RC) and 0.857 for the (WL), 0.861 (RA) and finally 0.548 was for (job performance). These findings indicated that $\mathrm{CR}$ for each variable is more than 0.70 ; thus, the suggestions indicate that the variables used are fully reliable. The minimum value for CR was 0.896 (WL) and maximum was 0.939 (RC). However, CR values of (RA) was 0.955 and (job performance) was 0.967 that given in Table 1 below.

Subsequently, HTMT was tested in discriminant validity for reflective scale measurement; the Henseler et al. (2015) indicates that heterotrait-monotrait ratio of correlations (HTMT) is based on the multitrait-multi method matrix to assess discriminant validity for reflective scale. The results show the reports from HTMT- criterion that discriminant validity had been established between constructs. Clearly, violations of HTMT has not been found between constructs measures in the current model. Totally, the measurement model established adequate convergent validity and discriminant validity for the current research on Private Universities.

\section{Findings and Discussion}

\subsection{Structural Model}

This study evaluated the using of path relationship via (collinearity Test, the level of $\mathrm{R}^{2}$, standard beta, $\mathrm{t}$-values) of 1000 bootstrapping and resampling according to Hair et al. (2014). Also, the variance inflation factor should be checked since nature exogenous variables in this study collinearity test employed thought, any cause for variance inflation did not find. Albeit, the judgment of level of $\mathrm{R}^{2}$ value whether is high or low depends upon the nature of study context to (Hair et al. 2011) and results show that $\mathrm{R}^{2}$ value of endogenous variable is only (0.298) that means $29.8 \%$ of the variance in academic performance can be clarified by the exogenous variables (i.e. organizational stressors indicators: WL, RC, RA).

Further, the path coefficients have been analysed and 1000 bootstrap to assess the statistical significance of the structural model following that an examination of the beta and $t$ value shows in the Table 1. Therefore, hypothesis 1 , hypothesis 2 , and hypothesis s 3 have revealed that there is a direct negative relationship between stress indictors and academic performance in private universities.

Table 1. The outcomes of Hypothesis

\begin{tabular}{ccccc}
\hline Hypothesis & Direct Relationship & Beta & SE & t-value \\
\hline H1 & WL->JB & -0.067 & 0.092 & $2.965^{* *}$ \\
\hline H2 & RC->JB & -0.198 & 0.085 & $2.910^{* *}$ \\
\hline H3 & RA->JB & -0.217 & 0.901 & $2.911^{* *}$ \\
\hline
\end{tabular}

${ }^{*} \mathrm{p}<0.05 ; * * \mathrm{p}<0.01 ; \mathrm{RA}=$ role ambiguity, $\mathrm{RC}=$ role conflict, $\mathrm{WL}=$ workload, $\mathrm{SS}=$ social support, $\mathrm{T}$ value $=1.96$

\subsection{Results Discussion and Conclusion}

The focus of this research is to examine and test the effect of stress indicators in private academia organization and results of the current study confirmed that WL, RA and $\mathrm{RC}$ are associations of organizational stress indicators among academic personnel from private universities in Malaysia.

According to the findings, workload could be one of the organizational stress indicators and employed negative effect on job performance among academic personnel in private universities. Therefore, academic performance decreased dramatically when they encountered workload in their daily tasks and duties. It must be emphasized that, based on the current research framework and instruments, the amount of workload of academic personnel in private universities is determined via the task overload, deadlines, and other subsequent indicators such as task demand, time pressures and time arrangement of their duties and roles in the workplace too. It should be highlighted here that performance in the private universities is divided to teaching and research activities of academic staff.

According to Yousefi and Abdullah (2019), workload in Malaysian public universities has no impact on academic staff performance, while the result of the current study indicate that workload is the major indicator that has effect on private universities academic staff, however, based on the information that mentioned above, role ambiguity adversely impacts on performance and results extends the previous literature on this domain according to June and Mahmood (2011). In addition, the result indicates that academic personnel faced with ambiguities in their roles dealing with low performance in universities. Finally, the present research findings prove the past studies that conflicted academic staff encountered poor academic performance.

To sum up, it is important to recognize and separate these stress organizational indicators that have negative effect on academic performance because the differences in job demand theoretically have distinct constructs which induce different outcomes. Hence, policy makers, human resource managers and administrators in the private university would be well advised to figure out the root of these stress indicators by reviewing the requirements and responsibilities they bestow upon their academic staff. 
Accordingly, it elevates new domain and contributes to the policy makers in higher education sectors to take into their attention that the very explicit agenda about academic personnel expectation in workplace as well as establish crystal clear job description towards the roles. Finally, there are many directions for future study that could be based on this research. Specifically, the current study has investigated only three indicators in private universities, and it is substantial to address that still other indicators of stress in organization have not been recognized yet.

\section{REFERENCES}

[1] Ahsan, N., Abdullah, Z., Gun Fie, Y. D., \& Alam, S. (2009). A study of job stress on job satisfaction among University Staff in Malaysia: Empirical study. European Journal of Social Science, 8(1), 121-13.

[2] Baron, A. R., \& Greenberg, J. (2003). Organizational Behaviour in Organization. Understanding and managing the human side of work. Canada: Prentice Hall.

[3] Eisenberger, R., Jones, J. R., Stinglhamber, F., Shanock, L., \& Randal, A. (2005). Flow experiences at work: For high need achievers alone? Journal of Organizational Behavior, $26,755-775$.

[4] Fernandez, J. L. (2010). An exploratory study of factors influencing the decision of students to study at Universiti Sains Malaysia. 28(2), 107-136.

[5] Hair, J. F., Black, W. C., Babin, B. J., \& Anderson, R. E. (2010). Multivariate data analysis (7th ed.). Englewood Cliffs: Prentice Hall

[6] Hair, J. F., Hult, G. T. M., Ringle, C., \& Sarstedt, M. (2014). A primer on partial least squares structural equation: modeling (PLS-SEM): Sage Publications.

[7] Hair, J.F., Ringle, C. M. \& Sarstedt, M. (2011). PLS-SEM: Indeed, a silver bullet. Journal of Marketing Theory and Practice 19(2), 139-151.

[8] Henseler. J., Hubona. G., \& Ash Ray, P. (2016). Using PLS path modelling in new technology research: updated guidelines. Industrial Management \& Data Systems. https://doi.org/10.1108/IMDS-09-2015-0382.

[9] Henseler, J., Ringle, C. M., \& Sarstedt, M. (2015). A new criterion for assessing discriminant validity in variancebased structural equation modeling. Journal of the Academy of Marketing Science, 43(1), 115-135.

[10] Jacob, W. J., Xiong, W., \& Ye, H. (2015). Professional development programmes at world class universities. Palgrave Communications, 1, 15002.

[11] Jonker, L. C. (2016). Stress in a College Workplace and its Relationship with Certain Correlations and Predictive Variables. Stellenbosch University.

[12] June, S., \& Mahmood, R. (2011). The relationship between role ambiguity, competency and person-job fit with the job performance of employees in the service sector SMEs in
Malaysia. Business Management Dynamics, 1(2), 79-98.

[13] Kaur, A., Noman, M., \& Awang-Hashim, R. (2018). The role of goal orientations in students' perceptions of classroom assessment in higher education. Assessment \& Evaluation in Higher Education, 43(3), 461-472.

[14] Li, L. (2012). Role Ambiguity among School Principals in China and Finland. Retrieved from https://jyx.jyu.fi/bitstre am/handle/123456789/41912/URN:NBN:fi:jyu201307302 100.pdf?sequence $=1$

[15] Ling, S. M. (2014). An Investigation on Factors of Work Stress Influence Job Performance: Moderating by Social Support, (May), 115.

[16] Maree, J. G. (2010). The career interest profile (2nd ed.). Randburg, South Africa: Jopie van Rooyen and Partners.

[17] Murphy, J. (2014). Managing professional development of academic staff to enhance university performance. Thesis (Doctor of Business Administration (DBA). University of Bath.

[18] Podsakoff, P.M., MacKenzie, S.B., Lee, J.-Y., \& Podsakoff, N.P. (2003). Common method biases in behavioural research, a critical review of the literature and recommended remedies. Journal of Applied Psychology 88, 879-903.

[19] Sekaran, U., \& Bougie, R. (2010) Research methods for business: A Skill Building Approach (5th ed.). Chichester, West Sussex, UK: John Wiley \& Sons Ltd.

[20] Triantafillou, P. (2004). From blood to public office: Constituting bureaucratic rulers in colonial Malaya. Journal of Southeast Asian Studies, 35, 21-40.

[21] Yousefi, M., \& Abdullah, A. G. K. (2019). The Impact of Organizational Stressors on Job Performance among Academic Staff. International Journal of Instruction, 12(3), 561-576. doi: 10.29333/iji.2019.12334a.

[22] WHO (2016), Healthy Workplaces: A Model for Action for Employers, Workers, Policymakers and Practitioners, Geneva: World Health Organization. 